\title{
Application of Project-Based Learning in Analog Electronic Technology Course
}

\author{
Jian Fang \\ School of information and electrical engineering \\ The City College of Zhejiang University \\ Hangzhou, China
}

\author{
Shengying Zhao, Lina Shang, Xuanchang Zhou, Cui Zhang \\ School of information and electrical engineering \\ The City College of Zhejiang University \\ Hangzhou, China
}

\begin{abstract}
Analog electronic technology has a high demand for theory and application. Traditional classroom teaching makes students think this course is too difficult and too boring. The project-based learning is based on the design of the actual product, and emphasizes the autonomy, systematicness, practicality and creativity of learning. It is very suitable for engineering students. Audio power amplifier circuit includes the main components and circuits of analog electronic technology. In this paper, project-based learning is applied to analog electronic technology course, and the audio power amplifier circuit is chosen as the engineering project. The project is decomposed into different design stages, including project survey, scheme design, circuit schematic design, PCB layout design, circuit installation, welding and debugging. At each stage, students put forward their own problems, solve problems one by one through thinking and practice. In the process of project, students gradually understand the connection between theory and application, systematically master knowledge, and improve the ability to solve practical problems. The enthusiasm and enthusiasm of the students increased significantly. The teaching effect has been improved obviously.
\end{abstract}

Keywords-Project-based learning; Analog electronic technology; Practice teaching; Protel99se

\section{INTRODUCTION}

Traditional learning is centered on textbooks and teachers. The textbook abstracts the concrete knowledge from the life scene, and forms the abstract theory. Theoretical knowledge has been artificially filtered out of many complicated factors and become abstract, boring and isolated. For beginners, it is not easy to grasp the main points of knowledge, because they cannot fully understand the life prototype of knowledge systematically. Students are in a passive learning state, it is difficult to develop students' habit and ability to think independently [1]. Once students enter the society, facing the complex and ever-changing reality problems, they often have no way to start. Because there is no standard answer, you can refer to. Nowadays, with the rapid growth of knowledge, the traditional learning model has been unable to cultivate innovative talents [2].

The purpose of learning is to master knowledge, the purpose of mastering knowledge is to solve the problem. The problem-based learning was first introduced into the integrated curriculum education in American Medical schools [3]. The problem-based learning model restore the scene of life, guide students to find problems, analyze problems and solve problems. In this process, students transform theory into their own knowledge and improve their ability of independent thinking. At present, problem-based learning has become a popular teaching model in the world [4]. But problem-based learning is not applicable to all the learning sessions of all courses. Problem-based learning promotes students understanding by solving problems related to the real world. From understanding to application, it needs practice. However, the content of Problem-based learning is relatively independent and single, and there is a certain gap with complexity and practical problems. Therefore, project-based learning model is proposed. It is widely used in engineering teaching [5].

\section{PROJECT-BASED LEARNING MODEL}

Project-based learning is also known as PBL. The abbreviation of problem-based learning above is the same. In this paper, PBL refers to project-based learning. It takes the actual project as the core, decomposes the project into several stages of learning, and finally completes the project. Therefore, project-based learning can be viewed as a synthesis of problem-based learning models at multiple stages. PBL is generally used in practice teaching after theoretical study. This learning model highlights the systematic, practical and innovative learning, and is a very suitable learning mode for engineering majors [6]. Due to the development of information technology, learning resources are very rich, information access is very convenient and quick. This provides a good technical support platform for project-based learning. 


\section{A. The teaching process of $P B L$}

PBL takes the project as the core, arranges each stage of the teaching. In practice, it mainly includes six stages, as shown in Figure 1. The dotted line indicates the process that needs rework.

\section{1) Project design}

Project design is a very important step. The project selection should not only conform to the teaching content, but also consider the basis and interest of the students. In addition, the project with practicability and novelty can fully arouse the initiative and enthusiasm of the students.

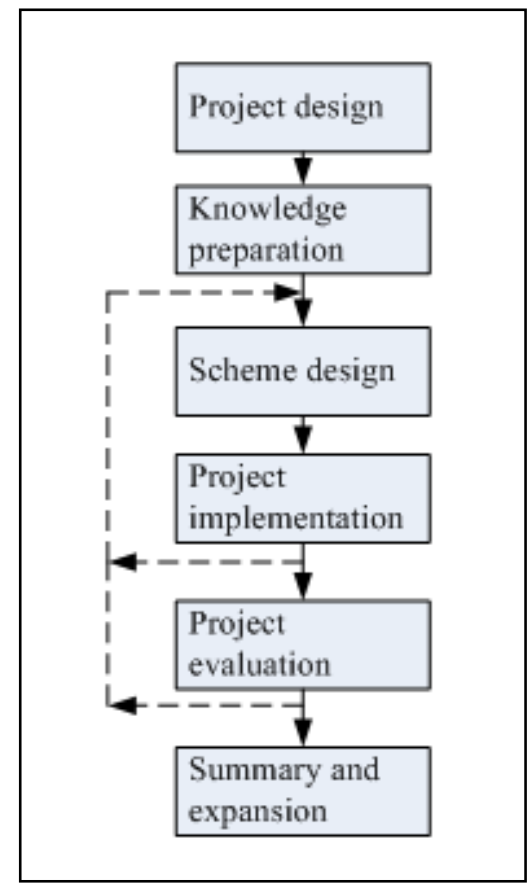

Fig. 1 PBL flow-process diagram

\section{2) Knowledge preparation}

Before the implementation of the project, the students need to grasp the corresponding theoretical knowledge and tools. Different from PBL's attention to individual problems, projectbased learning requires complete background knowledge and relevant theoretical foundations. This does not require that students have mastered all the relevant knowledge. Through the project design, students can verify the original knowledge, and make up for the missing parts of the knowledge chain, master the related tools and skills. Thus, students can develop systematic knowledge and ability.

\section{3) Scheme design}

Students are divided into groups. According to the requirements of the project, each group members discuss the design indicators, determine the appropriate project plan by looking for literature. This is the process of training students to understand problems, decompose problems, and find solutions to problems, and it is also a key step in PBL.

\section{4) Project implementation}

After the project plan is determined, students can enter the implementation stage. In this process, new problems will continue to emerge. This requires a more in-depth study to understand the project and ensure the completion of the project. At the same time, the effective use of tools and resources has a very big impact on the progress of the project implementation.

\section{5) Project evaluation}

The progress and completion of the project need to be evaluated. This is a comprehensive assessment of the effect of learning. The evaluation is based on the final results. There are many forms of evaluation, including individual self-assessment, intra group evaluation, inter group competition and teacher evaluation

\section{6) Summary and expansion}

The final step is a summary report in a text form. Through writing summary, we can strengthen the new knowledge and new skills learned in the project, expand ideas, and enhance the understanding of theory and application.

\section{B. The key points of $P B L$}

Whether the PBL can be carried out according to the teaching plan and whether it can achieve the desired teaching effect, we need to pay special attention to the following key points.

\section{1) Rationality of the project}

The content of the project should be specific, and it is best to be close to life. Students design real products, solve real problems, which can greatly improve the sense of achievement. The project should be diversified to prevent students from imitating simply. Project difficulty should be moderate. If the project is too simple, students can't learn anything new. If the project is too difficult, the students cannot finish it. This will not achieve the teaching effect, but also blow the enthusiasm of students. Projects should be easily decomposed. The project can be implemented step by step. Team members can work together. In a word, the reasonable project design can carry on smoothly in the other teaching process, and obtain better effect.

\section{2) Teacher's role}

In the process of PBL teaching, the role of teacher is multiple, which is not only the guider, but also the participant. Students master the autonomy of learning. Teachers should pay attention to guide students to think deeply. In the project design stage, the teacher guides the student to ask the question, analyzes the question. Teachers can give advice, but they don't provide answers. Teachers need to check the enforceability of the final program. At the stage of project implementation, teachers supervise the progress and encourage students' creative thinking. In the project evaluation stage, teachers stimulate the potential of students through the competition between groups. 


\section{3) The role of teams}

PBL adopts the mode of intra group cooperation and inter group competition. Students freely set up teams. Group members need to work together to analyze problems, solve problems, and have a division of labor, to do more in-depth study on a problem. Through the project, we develop students' team communication, cooperation and coordination ability. A successful PBL teaching must be the result of teamwork.

\section{THE APPLICATION OF PBL IN ANALOG ELECTRONIC TECHNOLOGY COURSE}

Analog electronic technology is the basic course of electrical and electronic specialty, which mainly includes the commonly used electronic devices and analog circuits. The course is mainly based on theoretical teaching and exercises analysis. Students lack of perceptual knowledge, lack of interest. Students cannot use knowledge to analyze and design circuits. Therefore, it is necessary to adopt PBL to design the practical course of analog electronic technology [7]. The following illustrates the application of PBL teaching in the course.

\section{1) Project design}

Audio power amplifier is a device used to drive the sound of a loudspeaker and reproduce the sound. Audio power amplifier is widely used in mobile phones, computer speakers, home theater and other electronic equipment. At the beginning, the course shows the effect of the work first, which makes the students have a strong impression and stimulate their interest and enthusiasm in learning.

The audio power amplifier actually amplifies the smaller audio signals, increases their power, and then outputs them. The preamplifier is mainly used to amplify the small signal. It uses a same direction amplifying circuit to enlarge the voltage of the input small signal. The latter stage mainly amplifies the power so that it can drive the resistor to obtain the required audio output. The project includes common electronic devices, such as capacitors, resistors, diodes, three stage transistors and integrated chips. The project includes the basic circuit, such as op amp circuit, power amplifier circuit, frequency regulation circuit and power circuit. So the design of audio power amplifier circuit is the comprehensive application of analog electronic technology knowledge.

Audio power amplifier has a lot of mature products. A large number of references can be consulted. The project only gives the following technical indicators: (1) tuner input range: 50$500 \mathrm{mV}$; microphone input range: $1-5 \mathrm{mV}$. (2) Load impedance: $\mathrm{RL}=4 \mathrm{ohm}$; rated power: $\mathrm{Po}=10 \mathrm{~W}$; bandwidth range is not less than $50 \mathrm{~Hz}-10 \mathrm{KHz}$; (3) tone control: Bass $100 \mathrm{~Hz}+12 \mathrm{~dB}$; treble $10 \mathrm{KHz}+12 \mathrm{~dB}$ (4) design meet the requirements of the regulated power supply circuit.

Therefore, project design is practical, open, diverse and attractive.

\section{2) Knowledge preparation}

Theoretical teaching emphasizes the principles and operations, and there is a gap with practical engineering applications. So it is necessary to carry out some special knowledge, including: capacitor and application circuit; diode device and application circuit; integrated operational amplifier circuit; a typical audio amplifier; DC power supply circuit; Protel schematic diagram design; Protel PCB design; welding technology and circuit debugging. These topics are arranged at different stages of the course, which makes the learning more targeted.

\section{3) Scheme design}

3-4 people are divided into one group. Both autonomous learning and group discussion. In addition, the plea exchange of group plan is arranged. First, students learn background knowledge through survey, and analyze project requirements. Then the block diagram of audio power amplifier system is determined by group discussion and inter group oral defense. Figure 2 is a block diagram of a reference system, including a microphone amplifier circuit, a preamplifier circuit, a tone control circuit, a power amplifier circuit and a power supply circuit. Then each group discussed the specific design scheme of each module. Finally, students select the appropriate chips and components, and calculate the component parameters, determine the detailed schematic diagram. Through this discussion and study, students realize that the circuit equipment is no longer an isolated part, but a part of the complete system. The circuit knowledge is no longer a tedious theoretical calculation, but a mathematical tool to analyze the signal changes. Program design is the key to train students to analyze circuit and design circuit. The feasibility of the whole program needs teachers' participation and guidance.

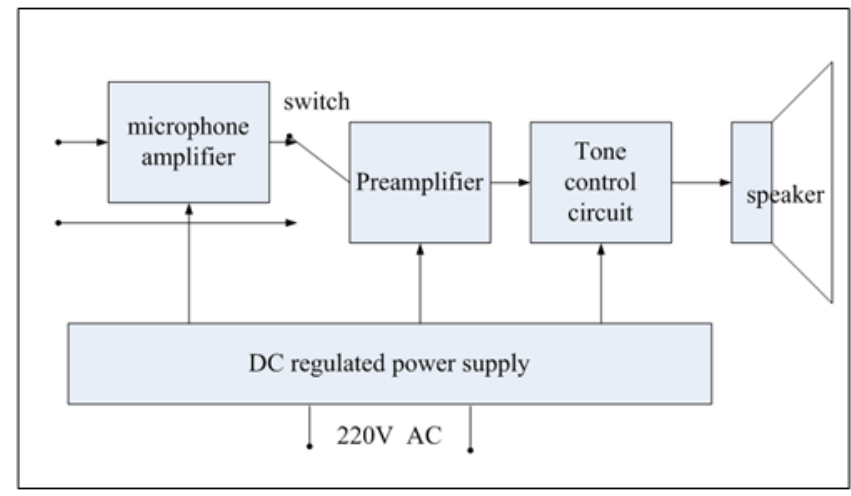

Fig. 2 System block diagram

\section{4) Project implementation}

Project implementation includes schematic design, PCB design, circuit welding and commissioning. Schematic design and PCB design were completed using Protel99se software. The project only requires students to master the basic functions of the software, to complete the circuit design. The advanced learning of software will be carried out through future projects. Use software as a project tool, and don't become a burden of learning. Figure 3 is audio power amplifier reference schematic. Figure 4 are audio power amplifier reference PCB layout. 
For the students, the circuit installation and welding is a favorite part. Students deepen the perceptual knowledge of devices and circuits. Students' practical ability has also been strengthened. Circuit debugging can strengthen the students' ability to analyze the circuit, including how to correctly use detection tools, how to locate the problem point, how to test their own judgment, how to solve the problem.

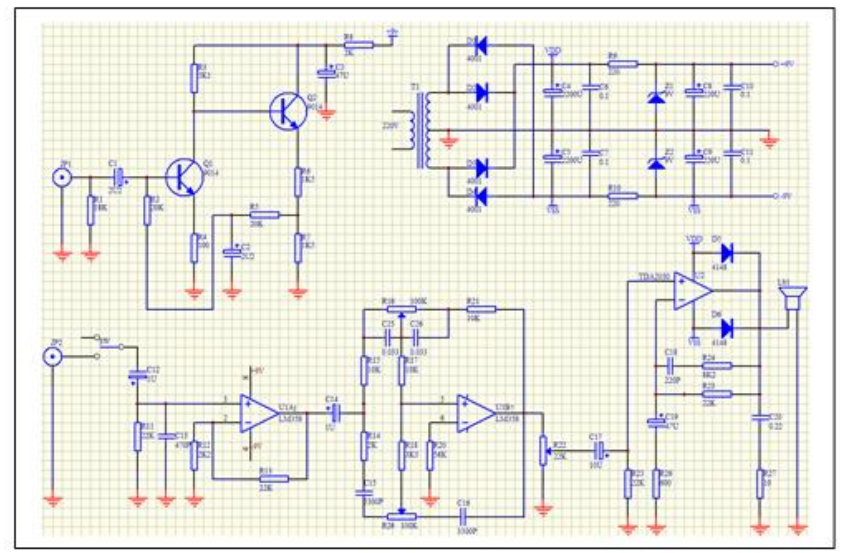

Fig. 3 System block diagram

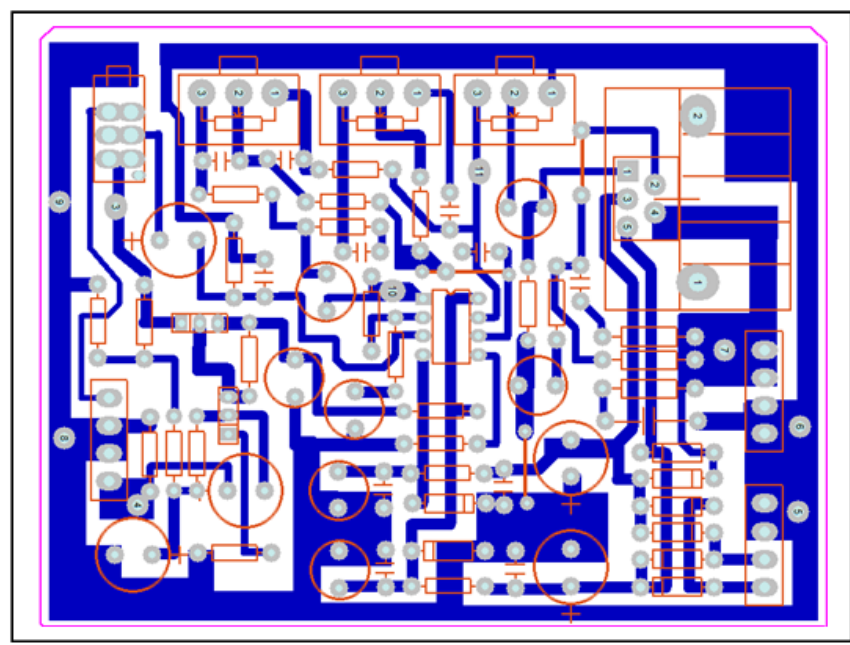

Fig. 4 System block diagram

\section{5) Project evaluation}

Project evaluation is no longer a simple teacher evaluation, but divided into these parts. Results function and performance accounted for $50 \%$. Because it is project-based learning, it must be based on the results of the project. Oral defense accounts for $30 \%$, and benign competition between groups can improve the learning effect. Team members scored each other, accounting for $10 \%$. The team members are graded according to their contribution to the project, which can stimulate the enthusiasm of the students. Project reports accounted for $10 \%$. This kind of comprehensive evaluation can reflect the actual participation and completion of students, and the scores are more reasonable

6) Summary and expansion

After the completion of the project, students need to sort out, summarize and reflect in time, and record the whole thinking and practice process in the form of documents. To sort out new knowledge, new tools and skills. To summarize the links between theoretical knowledge and practical projects, to summarize the methods of finding problems, thinking problems and solving problems. Compared with the results among different groups, to reflect the difference of the Schemes .To improve the design.

\section{SUMMARY}

PBL takes the project as the core, the goal is very clear and specific, and it is easy to mobilize the enthusiasm of students. In the process of project, one by one targeted problems are triggered, which can stimulate students' learning initiative and creativity. PBL has been applied to analog electronic technology practice course, and has achieved obvious teaching effect. Of course, real commercial products also need to consider the factors of appearance design, cost, manufacture, etc. This requires an interdisciplinary team of students to design a higher level of project-based learning, which makes the learning process even better.

\section{ACKNOWLEDGMENT}

This paper is supported by Hangzhou City special Specialty construction fund- Communication Engineering.

\section{REFERENCES}

[1] Lihua Ye, Yiping cui, Guohua Hu, The Exploration of Teching Reform in the Course of Optoelectronic Technology[J],JOURAL OF EEE, 2007,29(2):10-12. (In Chinese)

[2] Xiaoming Guo , Theoretical discussion on Curriculum Model [J]. Curriculum, teaching materials and teaching methods,2001(2): 29 -30. (In Chinese)

[3] Yin Shan, Pei Zhang, Application of TBL teaching method in theoretical teaching of clinical immunology for Postgraduates [J]. Chin J Immunol, 2015, 31(3): 408-409. (In Chinese)

[4] P. Schwartz, S. Mennin and G. Webb, Problem-based learning:case studies, experience and practice[M]. London: Kogan Page, 2001.

[5] Stephanie Bell. Project-Based Learning for the 21st Century: Skills for the Future $[\mathrm{J}]$. Clearing House A Journal of Educational Strategies Issues \& Ideas, 2010, 83(2):39-43.

[6] Mills J E, Treagust D F. Engineering Education, Is Problem-Based or Project-Based Learning the Answer [J]. Australasian Journal of Engineering Education, 2003, 3(4):205-207.

[7] Phyllis C. Blumenfeld, Elliot Soloway, Ronald W. Marx, et al. Motivating Project-Based Learning: Sustaining the Doing, Supporting the Learning [J]. Educational Psychologist, 2016, 26(3-4):369-398. 